\title{
Análise das Políticas Públicas Implementadas para a Gestão dos Recursos Hídricos no Brasil
}

\author{
Analysis of Public Policies Implemented for Water Management in Brazil
}

\author{
Jocemar Santos de Souza e Beatriz Stoll Moraes \\ Universidade Federal do Pampa \\ jocemarssouza@bol.com.br; beatrizstoll@gmail.com
}

\begin{abstract}
Resumo
Apesar do planeta ser coberto 70\% por água, a má distribuição deste mineral faz com que algumas áreas do globo terrestre sofram com a sua falta. Mesmo o Brasil sendo privilegiado com 13\% da água doce de todo o Planeta, fez-se necessário a criação e implantação de leis para sua preservação. O presente artigo tem como objetivo apresentar o histórico da Legislação Brasileira relacionada com a Gestão dos Recursos Hidricos, desde sua implantação até o período atual. De acordo com a bibliografia consultada, percebe-se que a preocupação com os recursos hídricos no Brasil era inicialmente para navegação e agricultura. A partir do ano de 1934, o Código de Águas passou a incentivar o uso industrial dos Recursos Hidricos, definindo a água como bem de uso público, comum ou particular. Somente com a implantação da Lei 9.433/1997, denominada Política Nacional dos Recursos Hídricos (PNRH) é que se passou a dar mais importância para gestão sustentável das águas, com padrões de qualidade satisfatórios para os diversos tipos de uso. Em 2000 foi criada a Agência Nacional de Águas (Lei 9.984), que possui como principais características disciplinar a implementação, a operacionalização, o controle e a avaliação dos instrumentos de gestão criados pela PNRH.
\end{abstract}

Palavras-chave: Recursos Hidricos. Politicas Públicas. Gestão Pública

\begin{abstract}
Although the planet is covered by $70 \%$ water, poor distribution of this mineral causes some areas of the globe suffer from its lack. Even Brazil being privileged with 13\% of freshwater around the planet, it was necessary the creation and implementation of laws for its preservation. This article aims to present the history of Brazilian legislation related to Water Management, since its inception to the current period. According to the bibliography, it is clear that concern for water resources in Brazil was initially for navigation and agriculture. From the year 1934, the Water Code went on to encourage the industrial use of water resources, defining water as a public good, common or private use. Only with the implementation of Law 9,433 / 1997, called the National Water Resources Policy (PNRH) is what happened to give more importance to sustainable water management, with satisfactory quality standards for the various types of use. In 2000 it was created the National Water Agency (Law 9984), which has as main features the disciplinary implementation, operation, control and evaluation of management instruments created by PNRH.
\end{abstract}

Keywords: Water Resources. Public Policy. Public Management. 


\section{Introdução}

Nas últimas décadas, têm-se discutido muito sobre a crise hídrica em nosso planeta. Apesar da Terra ser aproximadamente $70 \%$ coberta por água, apenas $2,5 \%$ deste montante é de água doce, sendo a maior parte encontrada em geleiras e em aquíferos de difícil acesso. Outro fator importante é a distribuição de forma desproporcional desta, o que faz com que algumas regiões do planeta sofram com a falta d'água e que em outros locais, este bem tão precioso para vida se torne abundante.

Porém, nada mais preocupante para crescente falta d'água, do que a falta de consciência dos seres humanos, seja no uso excessivo deste mineral, seja no alto índice de poluição dos lençóis freáticos. Para Nogueira (2006) a água do Planeta não vai acabar e nem está diminuindo. $\mathrm{O}$ que vem ocorrendo é uma diminuição de água potável devido à forma com que o Homem vem se utilizando dos recursos hídricos existentes, ou seja, o que falta é uma melhor gestão deste recurso.

O Brasil é um dos países mais privilegiados do mundo no que diz respeito à quantidade de água. Com $13 \%$ do total mundial, possui a maior reserva de água doce da Terra, porém, sua distribuição não é uniforme em todo o território nacional. Como exemplo desta má distribuição, pode-se citar a região amazônica, detentora da maior bacia fluvial do mundo e o Nordeste, que possui apenas 3\% da água doce do país (ANA, 2013).

Diante disso, o conhecimento de medidas legais e políticas públicas adotadas pelo poder público, fazem com que a sociedade em geral possa cobrar melhor de seus governantes o cumprimento de Leis já existentes, e que, se cumpridas, podem colaborar em muito para preservação dos Recursos Hídricos do Brasil.

Para Almeida (2010) e Farias (2009), as fases que marcam o histórico legal da proteção aos recursos naturais e da gestão dos recursos hídricos no Brasil não ocorreram de forma cronológica, ou seja, não se pode identificar exatamente onde uma começou ou terminou.

Este artigo procura apresentar a evolução legal na Proteção dos Recursos Hídricos no Brasil, desde o período de sua descoberta até o período contemporâneo, ou seja, expor as medidas jurídicas de proteção tomadas desde a fase do descobrimento em 1.500 até a fase de implantação da Política Nacional dos Recursos Hídricos.

\section{Materiais e Métodos}

O presente artigo baseou-se em uma revisão bibliográfica realizada entre agosto e outubro de 2015, onde foram consultados livros, periódicos, artigos científicos e pesquisas na internet. Como base de pesquisa na internet foram utilizadas as palavras-chave água, recursos hídricos, legislação, análise e Brasil.

Após, buscou-se estudar e compreender os principais parâmetros, histórico da legislação brasileira e sua aplicação na gestão nos recursos hídricos brasileiros.

\section{Legislação Brasileira Sobre os Recursos Hídricos}

Para a análise da legislação brasileira sobre os recursos Hídricos no Brasil, procurou-se realizar um estudo sobre as principais políticas públicas para gestão dos recursos hídricos desde os tempos do Brasil Colônia até a atual Política nacional dos Recursos Hídricos.

Inicialmente, vigorava no Brasil as Ordenações do Reino. Segundo essas Ordenações, os rios navegáveis e os que fossem possíveis se fazer navegáveis, caudalosos e que corressem todo o tempo, pertenciam aos direitos reais e a utilização dessas águas dependia de autorização régia (HENKES, 2004). No entanto, com a promulgação da Constituição do Império, a Ordenação se tornou inaplicável no Brasil e os direitos reais foram transferidos para o domínio nacional.

A Constituição do Império de 25/03/1824, não tratou diretamente do tema, porém, de acordo com o direito vigente à época, na propriedade do solo estava implícita a do subsolo, ou seja, as águas subterrâneas (POMPEU, 2010). Dessa forma, se houvessem mananciais de águas subterrâneas em terras privadas, estes pertenciam aos proprietários do solo. Esta constituição assegurava o direito de propriedade total em sua plenitude. Porém, também era previsto nesta Constituição que quando o poder público julgasse necessária a utilização dos recursos desta propriedade, o patrimônio particular poderia ser desapropriado mediante prévia indenização. Portanto, os mananciais hídricos existentes nas propriedades privadas poderiam ser desapropriadas pelo poder público, quando julgasse assim necessário. A citada Constituição não fez referências às águas superficiais (POMPEU, 2010).

A Constituição Republicana, de 24/02/1891, não orientou a que setor pertencia o domínio hídrico, ou seja, a quem pertencia a propriedade dos rios. Porém, determinou quem teria competência para legislar sobre a navegação dos mesmos. À União e aos Estados ficou estabelecido a competência para legislar sobre a navegação interior, e ao Congresso Nacional a competência para legislar sobre a navegação dos rios que banhassem mais de um estado ou se estendessem a territórios estrangeiros (GRANZIERIA, 2001).

O Código de Águas, (BRASIL, 1934), durante o primeiro governo de Getúlio Vargas, foi o 
marco legal do gerenciamento dos recursos hídricos no Brasil, tendo em vista que as constituições anteriores e demais normas infraconstitucionais normatizaram sobre outros aspectos, tais como domínio, propriedade e competências legislativas. A partir deste Código, o governo pode regulamentar o uso não só da água, como também de todos os minérios encontrados no subsolo. No entanto, através do artigo 118, a Lei separou a propriedade do solo da propriedade dos recursos minerais. Com isso, o governo de Getúlio Vargas deixava claro que a principal intenção do Estado com essa legislação era controlar e incentivar o uso industrial das águas. Dessa forma, o Código de Águas passou a dar ao poder público condições de controlar e incentivar o aproveitamento industrial das águas estabelecendo uma mudança nos conceitos de uso e propriedade definindo que a água brasileira poderia ser de uso público, comum ou particular.

Este código é considerado mundialmente como uma das mais completas leis de águas já produzidas, apesar da edição de normas posteriores, encontra-se vigente até os dias atuais, com ressalva para alguns dispositivos parcialmente ou totalmente revogados por leis posteriores. Quanto ao acesso da população para satisfação de suas necessidades básicas, o Código de Águas foi claro ao garantir tais direitos, mas não houve prioridade quanto ao abastecimento urbano.

A Constituição de 1937 acabou repetindo os dispositivos da constituição anterior referentes ao domínio hídrico, atribuindo à União competência privativa para legislar sobre as águas. Essa legislação demonstrou a mesma preocupação com a exploração econômica das águas (BRASIL, 1937).

A Constituição Republicana de 1946, considerada uma das mais modernas e liberais do país, efetuou mudanças significativas no tocante ao domínio dos recursos hídricos. O domínio da União expandiu-se bem como manteve a competência legislativa da União, a cerca dos recursos hídricos, no entanto, sem afastar a competência supletiva ou complementar dos estados (ANTUNES, 2002).

$\mathrm{O}$ alto índice de crescimento populacional, a aceleração da industrialização, o aumento da população urbana, a ineficácia na aplicação da maioria das legislações hídricas existentes e também a ausência de um planejamento visando a correta utilização dos recursos hídricos resultaram em profundas alterações no cenário hídrico brasileiro, principalmente a partir dos anos 70, o que fez com que novas medidas fossem tomadas na tentativa de alcançar uma melhor forma de utilização das águas, visando um desenvolvimento mais sustentável (REBOUÇAS, 2002).

Mundialmente, o principal marco na preocupação da gestão sustentável dos recursos naturais foi a conferência de Estocolmo, em 1972, que registrou o início da preocupação do sistema político com as questões ecológicas. Quanto a gestão de águas especificamente, destaca-se a Conferência das Nações Unidas sobre Água ocorrida em 1977 em Mar Del Plata, Uruguai, que lançou as bases para a tomada de posição da comunidade internacional em relação aos recursos hídricos, em razão da poluição e pela iminente escassez (VARGAS, 2000).

Em 1981, surge no Brasil a Lei 6.939 que disciplinou a Política Nacional do Meio Ambiente e instituiu o Sistema Nacional do Meio Ambiente SISNAMA, integrado por órgãos federais, estaduais e municipais, responsáveis pela proteção ambiental. Este Sistema possui como órgão máximo o Conselho Nacional do Meio Ambiente - CONAMA, o qual possui a competência, entre outras, "estabelecer normas, critérios e padrões relativos ao controle e à manutenção da qualidade do meio ambiente com vistas ao uso racional dos recursos ambientais, principalmente os hídricos" (BRASIL, 1981). No uso de suas competências, o CONAMA editou a Resolução 020, de 18/06/1986, que deu início, em âmbito nacional, a gestão de qualidade das águas, sendo este o instrumento legal utilizado para disciplinar a dinâmica de utilização das águas, até a promulgação da Lei 9.433/1997.

Em 1997, inspirada no modelo francês, surge a Lei $\mathrm{n}^{\circ} 9.433$ (BRASIL, 1997), denominada Política Nacional dos Recursos Hídrico (PNRH), consolidou a descentralização federal do gerenciamento do setor, ressaltando que este deve contar com a participação do poder público, dos usuários e da comunidade. Entre os fundamentos da PNRH figura a disposição de que a água é um bem de domínio público, recurso natural limitado e dotado de valor econômico. Esta Lei definiu que em caso de escassez, o uso dos recursos hídricos tem como prioridade o consumo humano e dessedentação de animais, e trás como um de seus principais objetivos assegurar à atual e às futuras gerações a necessária disponibilidade de água, em padrões de qualidade adequados aos respectivos usos.

Dentre as diretrizes gerais de ação para implementação da Política Nacional de Recursos Hídricos figuram:

I - a gestão sistemática dos recursos hídricos, sem dissociação dos aspectos de quantidade e qualidade;

II - a adequação da gestão de recursos hídricos às diversidades físicas, bióticas, demográficas, econômicas, sociais e culturais das diversas regiões do País;

III - a integração da gestão de recursos hídricos com a gestão ambiental;

IV - a articulação do planejamento de recursos hídricos com o dos setores usuários e com os planejamentos regional, estadual e nacional;

V - a articulação da gestão de recursos hídricos com a do uso do solo;

VI - a integração da gestão das bacias hidrográficas com a dos sistemas estuarinos e zonas costeiras (BRASIL, 1997).

Da leitura dos tópicos anteriores, entende-se a preocupação do legislador com o desenvolvimento sustentável e a gestão integrada e sistemática dos 
recursos hídricos, assegurada a participação dos usuários e da sociedade civil, a fim de garantir a oferta de água em quantidade suficiente e com qualidade satisfatória para as atuais e futuras gerações, além de resguardar o uso múltiplo das águas. Antes de tudo a Lei 9.433, de 1997, mostra-se um importante mecanismo de planejamento da exploração das águas.

Para serem colocadas em prática e não serem excluídas do cotidiano do gerenciamento hídrico, as diretrizes precisam estar inseridas nas várias etapas dos procedimentos de outorga do direito de uso das águas, na elaboração dos Planos de Recursos Hídricos e na efetivação do sistema de cobrança pelo uso das águas (MACHADO, 2002).

O Sistema Nacional de Gerenciamento de Recursos hídricos (SINGREH), criado pela Lei $n^{\circ}$ 9.433, de 1997 traz uma organização diferente da estrutura administrativa existente (União, estados, Distrito federal e municípios). Esta lei cria organismos necessários à execução das novas atividades, as quais, por terem base territorial diferente da divisão político-administrativa do país, não poderiam ser exercidas pelos órgãos existentes, que têm base municipal, estadual ou federal. As Agências de Água têm como área de atuação uma ou mais bacias hidrográficas e suas competências primordiais são o planejamento dos recursos hídricos da bacia e a cobrança pelo uso da água (KETTELHUT, 1999).

Com esta lei, o Estado cede parcela dos seus poderes, e o poder decisório passa a ser compartilhado nos Comitês de Bacia Hidrográfica e nos conselhos Nacional ou Estadual de Recursos Hídricos, autorizando a delegação da cobrança pelo uso das águas às Agências de Água, mas mantendo como atribuição do poder público conceder outorgas de direito de uso (BRASIL, 1997). A lei procura assegurar ao sistema viabilidade financeira destinando parte dos recursos arrecadados com a cobrança pela utilização da água ao custeio dos organismos que integram o sistema e ao financiamento das intervenções identificadas pelo processo de planejamento, e viabilidade administrativa ao criar organismos de apoio técnico, financeiro e administrativo aos colegiados do sistema.

A Lei $n^{\circ} .9 .433$, de 1997, modificada pela Lei $n^{\circ} .9 .984$ de 17 de julho de 2000 criou a Agência Nacional das Águas (ANA). A ANA possui características institucionais e operacionais um pouco diferentes das demais agências reguladoras, e a ela cabe disciplinar a implementação, a operacionalização, o controle e a avaliação dos instrumentos de gestão criados pela Política Nacional de Recursos Hídricos (PNRH). Dessa forma, sua perspectiva de regulação ultrapassa os limites das bacias hidrográficas com rios de domínio da União, pois alcança aspectos institucionais relacionados à regulação dos recursos hídricos no âmbito nacional.
Outras atividades da ANA são as de estímulo à criação dos comitês de bacias hidrográficas. Compostos por representantes da sociedade civil, dos usuários da água e dos poderes públicos, os comitês desempenham um importante papel nas ações de regulação, pois aprovam a aplicação adequada dos instrumentos de gestão na bacia. Essas entidades proporcionam que se cumpra, de forma descentralizada, a regulação eficiente (ANA, 2015).

A Lei $n^{\circ}$ 9.443/97 atribuiu ao Poder Executivo Federal a tarefa de implementar o Sistema Nacional de Gerenciamento de Recursos Hídricos (Singreh) e a Política Nacional de Recursos Hídricos. Além disso, criou uma autoridade responsável pela emissão de outorgas de direito de uso de recursos hídricos em rios sob domínio da União, ou seja, aqueles que atravessam mais de um estado, os transfronteiriços e os reservatórios construídos com recursos da União. Como uma de suas atribuições previstas na PNRH, a Agência Nacional de Águas estimula e apoia iniciativas voltadas à criação e fortalecimento de entes do Singreh e a implantação e operacionalização da gestão integrada de recursos hídricos. $\mathrm{O}$ apoio à implementação da gestão de recursos hídricos nos estados é feito por meio da celebração de convênios de cooperação entre a Agência e os órgãos gestores estaduais.

A ANA também trabalha na capacitação dos atores do Singreh, na promoção e execução de projetos e programas educativos voltados para a sociedade brasileira no que se refere à participação na gestão de recursos hídricos e à adoção de práticas de uso racional e conservação da água ANA, 2015).

O Singreh é constituído por: Conselho Nacional de Recursos Hídricos (CNRH); Secretaria de Recursos Hídricos e Ambiente Urbano (SRHAU) do Ministério do Meio Ambiente (MMA) Secretaria Executiva do CNRH; ANA; Comitês de Bacia Hidrográfica; Órgãos do poder público federal, estadual e municipal, cujas competências se relacionam com a gestão de recursos hídricos; Agência de Águas (SANTOS, 2002).

O Conselho Nacional de Recursos Hídricos é o órgão deliberativo e normativo mais elevado na hierarquia do Sistema Nacional de Recursos Hídricos, em termos administrativos, ao qual cabe decidir sobre as grandes questões do setor, além de dirimir as contendas de maior vulto. Regulamentado por meio do Decreto Federal $\mathrm{n}^{\circ} 2.612$, de 3 de junho de 1998, o CNRH é o órgão máximo normativo e deliberativo (BRASIL, 1998). A Secretaria Executiva do Conselho Nacional de Recursos Hídricos é exercida pela Secretaria de Recursos Hídricos e Ambientes Urbanos do Ministério do Meio Ambiente, cuja competência é prestar apoio administrativo, técnico e financeiro ao Conselho Nacional de Recursos Hídricos e coordenar a elaboração do Plano Nacional de Recursos Hídricos e encaminhá-lo à aprovação do Conselho. 
O CNRH possui 10 Câmaras Técnicas temáticas para tratar de assuntos pertinentes às suas atribuições, com o objetivo de subsidiar as decisões dos conselheiros em plenário.

O Comitê de Bacia Hidrográfica é um tipo de organização inteiramente nova na realidade institucional brasileira que conta com a participação dos usuários, das prefeituras, da sociedade civil organizada, dos demais níveis de governos estaduais e federal. O comitê de bacias é um ente de Estado, colegiado, responsável pela gestão das águas, no âmbito de uma bacia hidrográfica, com função política e administrativa. É um fórum de negociação fundamental nos conflitos da água, constituído por representantes do poder público, usuários e sociedade civil e tem caráter consultivo e deliberativo, destinado a atuar como "parlamento das águas da bacia", pois o comitê é o fórum de decisão, no âmbito de cada bacia hidrográfica (ANA, 2011).

O Comitê de Bacia Hidrográfica é composto por representantes da União, representantes dos Estados e do Distrito Federal, e representantes dos Municípios cujos territórios se situem, ainda que parcialmente, em sua área de atuação; representantes dos usuários das águas da área referida; e representantes das entidades civis de recursos hídricos, com atuação comprovada na Bacia. A representação dos Poderes Executivos da União, Estados, Distrito Federal e Municípios, nos Comitês de Bacia Hidrográfica é limitada a até metade do total dos membros que o constituem o Comitê (ANA, 2011). Nos Comitês de Bacias de rios fronteiriços e transfronteiriços, a representação da União deverá incluir o Ministério das Relações Exteriores e, naqueles cujos territórios abranjam terras indígenas, representantes da Fundação Nacional do Índio FUNAI e das comunidades indígenas.

As Agências de Água têm como área de atuação uma ou mais bacias hidrográficas. Quando instituídas, exercem a função de secretarias executivas de seus correspondentes comitês de bacia hidrográfica, servindo como o braço técnico dos mesmos. As competências primordiais dessas Agências são relativas ao planejamento dos recursos hídricos da bacia e à gerência dos recursos oriundos da cobrança pelo uso da água (KETTELHUT et al., 1999). A criação de uma Agência de Bacia depende da autorização do Conselho Nacional de Recursos Hídricos, ou dos Conselhos Estaduais de Recursos Hídricos, mediante solicitação de um ou mais Comitês de Bacia Hidrográfica, desde que demonstrem a sua viabilidade financeira. Isto é, que os recursos financeiros arrecadados pela Agência de Bacia, especialmente com a implantação do instrumento de cobrança pelo uso dos recursos hídricos, sejam suficientes para a sua autonomia financeira.

\section{Políticas Públicas Para Conservação dos Recursos Hídricos no Brasil}

No Brasil, a implantação de políticas públicas referentes aos recursos hídricos de domínio da União está concentrada na ANA. Dos vários programas conduzidos pela entidade, destacam-se em âmbito nacional os seguintes:

PRODES - Programa Despoluição de Bacias Hidrográficas, criado em março de 2001, também conhecido com "programa de compra de esgoto tratado", não tem como objetivo financiar obras ou equipamentos, mas sim o pagamento pelos resultados alcançados, ou seja, pelo esgoto efetivamente tratado. Este concede estímulo financeiro por parte da União, na forma de pagamento pelo esgoto tratado, para Prestadores de Serviço de Saneamento que investem na implantação e operação de estações de tratamento de esgotos, desde que cumpridas as condições previstas em contrato (ANA, 2001).

Produtor de Água: O objetivo deste programa é a redução da erosão e do assoreamento dos mananciais nas áreas rurais. Este programa é de adesão voluntária, prevê o apoio técnico e financeiro à execução de ações para conservação do solo e da água, como por exemplo, a readequação de estradas vicinais, a construção de terraços e bacias de infiltração, o reflorestamento de áreas de proteção permanente e reserva legal, a recuperação e proteção de nascentes, o saneamento ambiental, entre outros. Aos produtores rurais que, comprovadamente, contribuem para a proteção e recuperação de mananciais, gerando benefícios para a bacia e a população, o programa prevê o pagamento de incentivos, ou seja, uma espécie de compensação financeira.

A concessão dos incentivos ocorre somente após a implantação, parcial ou total das ações e práticas conservacionistas previamente contratadas. Os valores pagos aos produtores são calculados de acordo com os resultados pelo abatimento da erosão e da sedimentação, redução da poluição difusa e aumento da infiltração de água no solo (ANA, 2015).

Programa Nacional de Avaliação da Qualidade das Águas (PNQA): tem como meta oferecer à sociedade conhecimento adequado da qualidade das águas superficiais brasileiras, para subsidiar os tomadores de decisão (agências governamentais, ministérios, órgãos gestores de recursos hídricos e de meio ambiente) na definição de políticas públicas para a recuperação da qualidade das águas, contribuindo com a gestão sustentável dos recursos hídricos. O PNQA surgiu da constatação de uma série de questões, como a existência de lacunas geográficas e temporais no monitoramento da qualidade da água no Brasil, a falta de padronização e de informações sobre a realização das coletas e análises laboratoriais, o que torna os resultados 
existentes, muitas vezes, pouco confiáveis e de difícil comparação entre regiões distintas (ANA, 2015).

\section{Conclusões}

Apesar de o Brasil possuir enorme capacidade hídrica, podemos concluir que este recurso sempre esteve entre as principais preocupações da sociedade e dos governantes do país.

Porém, a gestão da água sempre acompanhou os interesses econômicos de cada época. Nos tempos do Brasil Colônia, a principal preocupação para o uso da água era para a navegação. Durante o governo de Getúlio Vargas, a utilização dos recursos hídricos passou a ser também para uso na indústria, sendo definido que a água pode ser de uso público, comum ou particular.

A partir da década de 1990, foi implantada no Brasil a Política Nacional dos Recursos Hídricos deixando o poder sobre as águas com a União, Estados e Distrito Federal. Durante este período passou-se a dividir esta gestão com os usuários e a sociedade civil, procurando preservar este recurso para as gerações futuras, buscando um desenvolvimento sustentável para os vários tipos de uso da água.

A implantação de políticas públicas ajuda em muito na conservação desse bem mineral, principalmente através da Agência Nacional das águas. Contudo, para que se consiga êxito na sustentabilidade do uso dos recursos hídricos, é necessário esforço não só dos governantes, mas principalmente da sociedade como um todo, seja na conservação, seja na fiscalização da utilização das águas.

\section{Referências}

ALMEIDA, C. C. de. (2002) Evolução Histórica da Proteção Jurídica das Águas no Brasil. Revista Jus Navigandi, Teresina, ano 7, n. 60, $1^{\circ}$ nov. 2002. Disponível em: $<$ http://jus.com.br/artigos/3421>. Acessado em 17/09/2015.

ANA (AGÊNCIA NACIONAL DE ÁGUAS). O Comitê de Bacia Hidrográfica, Prática e Procedimento, 2011. Volume 2. Disponível em:< http://capacitacao.ana.gov.br/Lists/Cursos_Anexos/A ttachments/90/miolo_comite2_final.pdf $>$ - Acessado em: 30/08/2015.

ANA (AGÊNCIA NACIONAL DE ÁGUAS). Programa despoluição de Bacias Hidrográficas PRODES.
$<$ http://www.ana.gov.br/prodes/prodes.asp $>$. Acessado em: 02/08/2015.

ANA (AGÊNCIA NACIONAL DE ÁGUAS). Programa despoluição de Bacias Hidrográficas PRODES. Disponível em:< http://www2.ana.gov.br/Paginas/projetos/ProgramaPr odutorAgua.aspx>. Acessado em: 02/08/2015.

ANA (AGÊNCIA NACIONAL DE ÁGUAS). Programa despoluição de Bacias Hidrográficas PRODES. Disponível em:< http://www2.ana.gov.br/Paginas/projetos/QualidadeA gua.aspx $>$. Acessado em: 02/08/2015.

ANA (AGÊNCIA NACIONAL DE ÁGUAS). Programa despoluição de Bacias Hidrográficas PRODES. Disponível em:< http://www2.ana.gov.br/Paginas/institucional/Sobrea Ana/Default.aspx>. Acessado em: 02/08/2015.

ANA (AGÊNCIA NACIONAL DE ÁGUAS). Conjuntura dos Recursos Hídricos no Brasil, 2013. Disponível em: $<$ http://arquivos.ana.gov.br/institucional/spr/conjuntu ra/webSite_relatorioConjuntura/projeto/index.html $>$. Acessado em 15/10/2015.

ANTUNES, P. de B. (2002) Direito Ambiental. $6^{\mathrm{a}}$ Ed. Rio de Janeiro: Lúmen Júris, 2002, 902p.

BRAGA, B.; REBOUÇAS, A. C. Águas Doces no Brasil. Capital ecológico, uso e conservação. São Paulo:Escrituras, 2002, 703p.

BRASIL, Lei 6.938/1981. Disponível em: $<$ http://www.planalto.gov.br/Ccivil_03/Leis/L6938.h tm>. Acessado em: 22/09/2015.

BRASIL. Presidência da República Federativa do Brasil. Constituição dos Estados Unidos do Brasil (19 de julho de 1934). Disponível em:

$<$ http://www.planalto.gov.br/ccivil_03/constituicao/C onstituicao34.htm>. Acessado em 15/08/2015.

BRASIL. Presidência da República Federativa do Brasil. Constituição dos Estados Unidos do Brasil (10 de novembro de 1937). Disponível em: $<$ http://www.planalto.gov.br/ccivil_03/Constituicao/ Constituicao37.htm>. Acessado em 14/08/2015. 
BRASIL. Presidência da República Federativa do Brasil. Decreto-Lei $\mathrm{n}^{\circ} 7.841 / 1945$. Disponível em:< http://www.planalto.gov.br/ccivil_03/DecretoLei/1937-1946/Del7841.htm>. Acessado em 01/08/2015.

BRASIL. Presidência da República Federativa do Brasil. Decreto-Lei no 2.612/1998. Disponível em:< http://www.planalto.gov.br/ccivil_03/decreto/D2612. htm $>$. Acessado em 30/08/2015.

FARIAS, T. (2009) Introdução ao Direito Ambiental. Belo Horizonte: Del Rey, 2009.

GRANZIEIRA, M. L. M. Direito de Águas e Meio Ambiente. São Paulo: Ícone, 1993. 136p.

HENKES, S. L. (2004) Histórico Legal e Institucional dos Recursos Hídricos no Brasil. Disponível em: $<$ http://www1.jus.com.br/doutrina/texto.asp?id=4146 >. 2004. Acessado em: 24/09/2015.

KETTELHUT, J.T. S. et. al. (1999) Aspectos Legais, Institucionais e Gerenciais. In: O Estado das Águas no Brasil. Brasília: ANEEL e ANA, 1.999.

MACHADO. Paulo Affonso Leme. Recursos Hídricos - Direito Brasileiro e Internacional. Malheiros Editores: São Paulo, 2002.

NOGUEIRA, R. Água: A Luta do Século. Rio de Janeiro: Editora Sol, 2006.

POMPEU, C. T. Direito de Águas no Brasil. 2 ed. São Paulo: Editora Revista dos Tribunais, 2010.

POMPEU, C. T. Regime Jurídico da Política das Águas Públicas. São Paulo: CETESB, 1976.

REBOUÇAS, A. C. Água Doce no Mundo e no Brasil. In: REBOUÇAS, A. C. et al. (orgs) Águas Doces no Brasil - Capital Ecológico, Uso e Conservação. São Paulo: Escrituras, 2002. 2 ${ }^{\mathrm{a}}$ Ed. Revisada e Ampliada.

SANTOS, Thereza Christina Carvalho e CÂMARA, João Batista Drummond (Orgs.). GEO Brasil 2002 - Perspectivas do Meio Ambiente no Brasil. Brasília: Edições IBAMA, 2002.

VARGAS, Everton Vieira. Água e Relações Internacionais. In Revista Brasileira de Política
Internacional, 2000, Volume 43, $\mathrm{n}^{\circ}$ 001. Brasília, Brasil. Disponível em: $<$ http://redalyc.uaemex.mx/redalyc/pdf/358/3584311 0.pdf $>$. Acessado em 22/09/2015. 